\title{
Refractive Outcomes of Retropupillary Fixated Iris-Claw Lens for Exchange of the Dislocated Intraocular Lens Using Modified Scleral Incisions
}

\author{
Hyungil Kim' \\ Sohee Jeon ${ }^{2}$ \\ 'Gyeongju St. Mary's Eye Clinic, \\ Gyeongju-si, Gyeongsangbuk-do, \\ Republic of Korea; ${ }^{2}$ Keye Eye Center, \\ Seoul, Republic of Korea
}

\begin{abstract}
Purpose: To evaluate refractive outcomes after retropupillary iris-claw intraocular lens (IOL) implantation and to compare postoperative astigmatism from (1) a conventional 5.5-mm sclerocorneal incision, (2) an L-shaped scleral tunnel incision, and (3) a frown scleral tunnel incision.

Methods: This was a retrospective study of eyes undergoing dislocated IOL exchange for a retropupillary iris-claw IOL. Uncorrected and corrected distance visual acuity (UDVA and CDVA) and postoperative complications were evaluated until postoperative months 24 . The refractive outcomes and the surgically induced astigmatism (SIA) vector were compared between groups.

Results: The medical records of 107 eyes from 107 patients with mean age of $65.31 \pm 12.15$ years were reviewed. Eyes with a frown incision showed the best UDVA, followed by those with L-shaped and conventional incisions $(P=0.003)$. Eyes with an L-shaped incision or frown incision had a lower SIA than that of the conventional incision group at postoperative 6 months (mean \pm standard deviation [SD] SIA, $0.86 \pm 0.85 \mathrm{D}, 0.63 \pm 0.37 \mathrm{D}$, and $1.70 \pm$ $1.27 \mathrm{D}$ for frown incision, L-shaped incision, and conventional incisions, respectively; $P=$ 0.004).
\end{abstract}

Conclusion: The frown incision and L-shaped incision induced a significantly smaller SIA than the conventional incisions, which was associated with better UDVA postoperatively.

Keywords: aphakia, astigmatism, intraocular lens dislocation, retropupillary iris-claw intraocular lens, scleral tunnel incision, sclerocorneal incision

\section{Introduction}

Implantation of an aphakic iris-claw intraocular lens (IOL) is used in aphakia or intraocular lens luxation/subluxation, when there is not adequate capsular support, but also as primary procedure during phacoemulsification in subluxated crystalline lens (ectopia lentis) and uncommon conditions with extremely large capsular bags (anterior megalophthalmos). ${ }^{1-11}$ Aphakic iris-claw IOL has been used since 1979 when was introduced by Worst. ${ }^{1}$ Soon later, a retropupillary model was described by Amar in $1980,{ }^{2}$ and retropupillary fixation of the standard aphakic iris-claw IOL was published by Rijneveld et al in $1994 .^{3}$ However, retropupillary approach has gained popularity more recently, in the last two decades, following the report by Mohr et al". ${ }^{1}$ Because the iris-claw IOL is fixed in the anterior or posterior surface of iris, it does not require scleral sutures. Accordingly, this procedure has several advantages, some of which include shorter surgical time and fewer postoperative
Correspondence: Sohee Jeon

Keye Eye Center, 326 Teheran-ro,

Gangnam-gu, Seoul, Korea

Tel +82-02-6207-I236

Fax +82-02-6207-1246

Email soheeeee@gmail.com 
suture-related or corneal complications. ${ }^{6-11}$ However, because the IOL is rigid, its implantation requires a large sclerocorneal incision, which often results in high surgically induced astigmatism (SIA). ${ }^{9,11-13}$

Substantial efforts to minimize postoperative astigmatism resulting from a 5.5- to $6.0-\mathrm{mm}$ sclerocorneal incision have been made previously, especially during the $1990 \mathrm{~s}$ when routine cataract surgery required a $6.0-\mathrm{mm}$ sclerocorneal incision. The most frequently used types of incision were the frown incision ${ }^{14}$ and the L-shaped incision. ${ }^{15}$ However, to our knowledge, there is only limited information available about the direct comparison between the refractive outcomes after retropupillary irisclaw IOL implantation using these modified sclerocorneal incisions.

In the present study, we evaluated the refractive outcomes after retropupillary iris-claw IOL implantation and compared the postoperative astigmatism resulting from (1) a conventional incision using a 5.5-mm sclerocorneal incision, (2) an L-shaped scleral tunnel incision, and (3) a frown scleral tunnel incision.

\section{Patients and Methods}

We retrospectively reviewed data from May 2, 2014, to December 31, 2020, of 107 eyes from 107 patients who underwent secondary implantation with Artisan aphakia iris-claw IOLs (Ophtec BV, Groningen, The Netherlands) at Gyeongju St. Mary's Eye Clinic. The Institutional Review Board (IRB)/Ethics Committee of Gyeongju St. Mary's Eye Clinic (IRB number: GSM-2021-1) approved the study and waived the requirement for informed consent because of the retrospective nature of the study. The patient data was maintained with confidentiality after anonymization. The study protocol adhered to the tenets of the Declaration of Helsinki.

The inclusion criteria comprised patients who underwent retropupillary Artisan aphakia iris-claw IOL implantation with a follow-up of more than 6 months. Eyes with vision-impairing eye disease at preoperative evaluation, such as age-related macular degeneration, diabetic retinopathy, or retinal vascular occlusions, were excluded from this investigation. Comprehensive preoperative ocular examinations, including uncorrected distance visual acuity (UDVA) and corrected distance visual acuity (CDVA), subjective and objective refraction, intraocular pressure measurement, slit-lamp examination, optical biometry measurement with a partial coherence interferometry device (IOLMaster 500, Carl Zeiss AG; Jena,
Germany), corneal topography using the HR Pentacam Scheimpflug System (Oculus Inc, Berlin, Germany), ultrawidefield fundus photography (Optos Optomap Panoramic 200A Imaging System; Optos plc, Dunfermline, Scotland), and three-dimensional (3D) optical coherence tomography (OCT)-2000 Spectral Domain OCT measurements (Topcon Medical Systems, Japan) were routinely performed. The IOL calculation was performed using existing built-in IOL formulas in the IOLMaster 500. The IOL power was selected to emmetropia, unless the fellow eye (without cataract or already pseudophakic) had a significant ametropia, in which case the power was calculated in such a way as to avoid anisometropia. The SRK/T formula with an optimized A constant of 116.9 (taken from the User Group for Laser Interference Biometry [ULIB] and IOL CON webpages) was used.

\section{Surgical Technique}

All surgeries were performed by one experienced surgeon (H.K.). Periocular anesthesia was performed using a $5-\mathrm{mL}$ mix of $4 \%$ lidocaine hydrochloride hydrate and $0.5 \%$ bupivacaine hydrochloride hydrate in a 1:1 ratio.

The corneoscleral incision was made using a $0.3-\mathrm{mm}-$ depth incision diamond blade by three different techniques depending on the time of the initial surgery: (1) conventional incision, (2) L-shaped incision, and (3) frown incision (Figure 1 and Supplemental Video 1). For the conventional incision group, a conventional $5.5-\mathrm{mm}$ sclerocorneal incision was made on the surgical limbus with a tunnel toward the $0.5-\mathrm{mm}$ cornea and sutured with 10-0 nylon at three points. The L-shaped incision was made, dividing the incision into two segments: the first of $2.75 \mathrm{~mm}$ in the surgical limbus and the second of $2.75 \mathrm{~mm}$ perpendicular to the first segment, and directed towards the sclera (hence its L-shaped name). Then, an anterior dissection was carried out in a plane approximately $300 \mu \mathrm{m}$ of the thickness using 300 $\mu \mathrm{m}$ restricted diamond knife to create a wide scleral tunnel that finally ended in an internal incision of approximately $5.5 \mathrm{~mm}$ in length. A suture was placed at the corner where the two incision segments met, and an additional suture was used if there was any leakage after placing the first one. The frown incision was made with a $5.5-\mathrm{mm}$ incision and a tunnel to the cornea and sutured at one central point.

A pars plana vitrectomy was performed for all cases as they had dislocated IOLs in the vitreous cavity or 

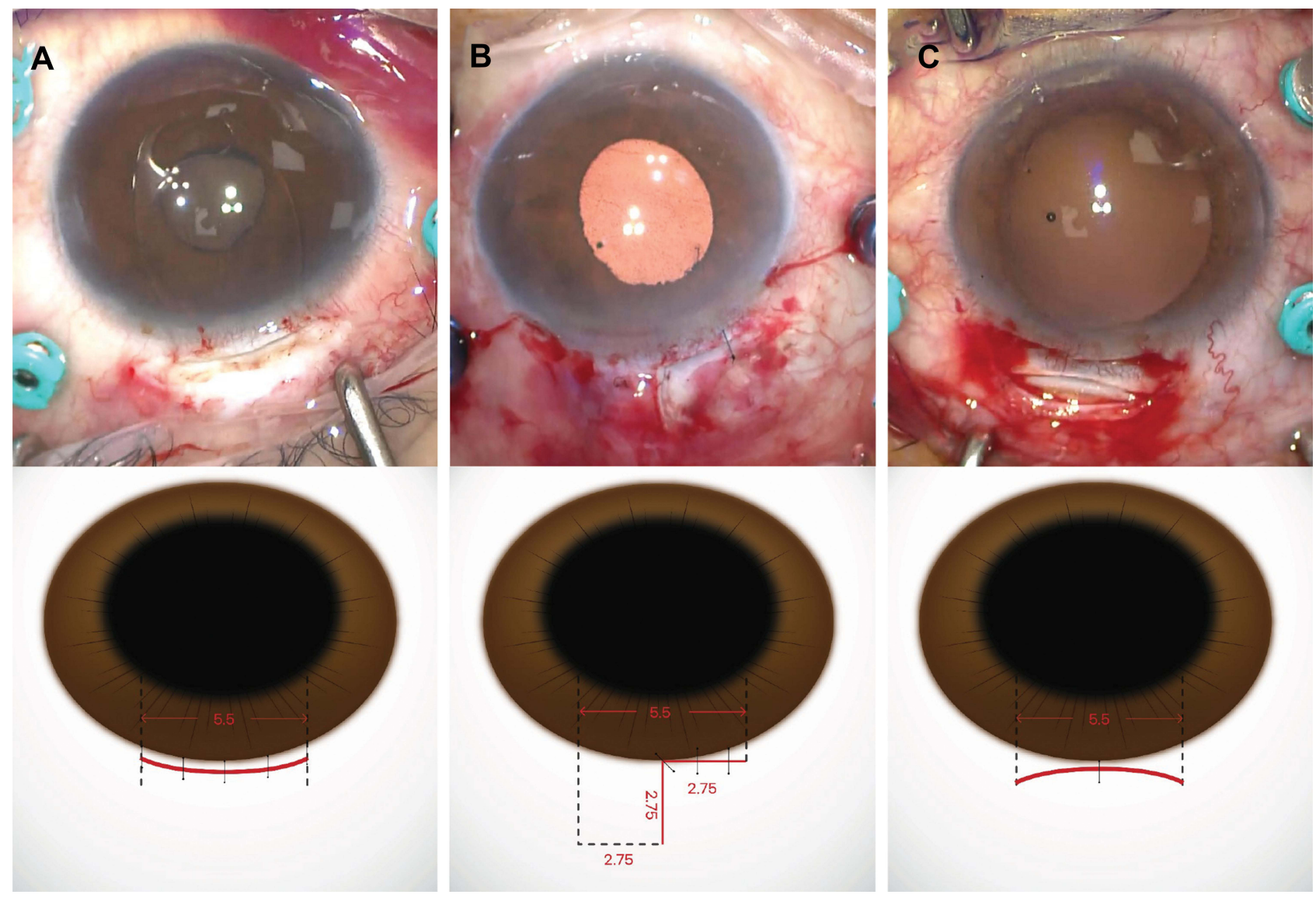

Figure I Representative photographs during the surgery and a schematic illustration of each incision type used; (A) a conventional 5.5-mm sclerocorneal incision, (B) L-shaped incision, and (C) frown incision.

incarcerated vitreous in the anterior chamber. The Artisan aphakia IOL was fixed into position on the posterior side of iris, with an enclavation needle, through two paracenteses at 1 1/2 and 10 1/2 o'clock (in small or sunken eyes), or with a spatula through two paracenteses at 3 and 9 o'clock (in standard or large eyes). All incision sites were sutured with 10-0 nylon. One drop of moxifloxacin $5 \mathrm{mg} / \mathrm{mL}$ (Vigamox; Alcon Laboratories, Inc. Fort Worth, Texas, USA) was topically applied four times daily, along with $0.1 \%$ Brom fenac sodium hydrate (Bronuck Ophthalmic Solution; Taejoon, Seoul, Korea) twice daily for 4 weeks and prednisolone acetate 1\% (Pred Forte; Allergan Inc. Irvine, CA, USA) four times a day for 10 days postoperatively.

\section{Outcome Measures}

Both UDVA and CDVA were evaluated at postoperative months $1,3,6,12$, and 24 using the decimal system and then converted into $\log$ MAR for statistical analysis. The refractive outcomes were analyzed according to the standard suggested by Reinstein et al. ${ }^{16}$ The polar notation of astigmatism (cylinder and meridian) was transformed into Cartesian (or rectangular) coordinates ( $\mathrm{x}$ and $\mathrm{y}$ ) according to the methods described by Alpins. ${ }^{17}$ The SIA vector at 6 months was calculated using the VectrAK analysis program which was available on the Alpins Statistical System for Ophthalmic Refractive Surgery Techniques (ASSORT) website (https://assort.com/) and reported as previously recommended. $^{18}$

\section{Statistical Analysis}

Statistical analyses were conducted using SPSS software, version 15.0 for Windows (SPSS Inc, Chicago, Illinois, United States). Descriptive data were recorded as mean \pm SD unless otherwise specified. The Shapiro-Wilk test was used to assess normality of the continuous variables. Twotailed $t$ tests were used to assess the differences in variables between groups. An analysis of variance (ANOVA) 
test was used for the comparison of three or more data. Bonferroni test was used for post-hoc analysis. The Pearson correlation coefficient was determined to assess the association between continuous variables, according to the normality of distribution. Independent variables significantly associated with scores in the univariate analysis $(P<0.05)$ and potentially confounding parameters were included as independent covariables in the multivariate analysis by multiple regression analysis. A two-sided $P$ value less than 0.05 was considered statistically significant.

\section{Results}

The medical records of 107 eyes from 107 patients (mean age \pm standard deviation [SD], $65.31 \pm 12.15$ years; range, 31-91 years; 80 men [74.8\%]) were reviewed in the present study. A total of 60 eyes (56.1\%) were in the conventional incision group (May 2014-December 2017), $29(27.1 \%)$ were in the L-shaped incision group (January 2018-August 2019), and 18 (16.8\%) were in the frown incision group (January 2020-December 2020). Table 1 shows the demographic and ophthalmologic data of this population. There was no difference between the groups in demographic or ophthalmologic data at baseline.

The visual and refractive outcomes after retropupillary iris-claw IOL implantation are summarized in Figure 2. The overall postoperative UDVA improved when compared with the preoperative CDVA (Figure 2A). UDVA from 88 of 104 eyes $(84.6 \%)$ was within one line of the CDVA (Figure 2B), and five of 104 eyes (4.1\%) lost two or more lines postoperatively (Figure $2 \mathrm{C}$ ). Four of five eyes $(80.0 \%)$ lost two or more lines due to cystoid macular edema and one of the five eyes $(20.0 \%)$ lost two or more lines from central serous chorioretinopathy. There was a tendency of under-correction (Figure 2D). The mean SE was $-0.14 \pm 0.83 \mathrm{D}$ at the 6-month postoperative visit; 71 of 104 eyes $(68.3 \%)$ were within $\pm 1.00 \mathrm{D}$ of the target refraction (Figure 2E). There was no significant myopic or hyperopic shift during the follow-up period (Figure 2F). However, the refractive astigmatism increased after retropupillary iris-claw IOL implantation (Figure 2G).

Postoperative refractive outcomes and visual acuities according to the subgroup are summarized in Table 2 . There was a significant difference in the UDVA between groups; eyes in the frown incision group showed the best UDVA followed by the L-shaped incision and conventional incision groups at postoperative 6 months ( $\log$ MAR visual acuity $\pm \mathrm{SD}, 0.06 \pm 0.11,0.24 \pm 0.23$, and $0.47 \pm 0.49$ for frown incision, L-shaped incision, and conventional incision, respectively; $P=0.003$, ANOVA test). Post hoc analysis using the Bonferroni test revealed the following: $P=0.151$ for conventional incision vs L-shaped incision, $P=0.536$ for L-shaped incision vs frown incision, and $P=0.003$ for frown incision vs conventional incision. The CDVA showed a similar distribution but was not significant ( $\log$ MAR visual acuity \pm SD, $0.02 \pm 0.05,0.15 \pm 0.24$, and $0.27 \pm 0.39$ for frown incision, L-shaped incision, and conventional incision, respectively; $P=0.035$ ). Post hoc analysis using the Bonferroni HSD test revealed the following: $P=0.089$ for conventional incision vs L-shaped incision, $P=0.728$ for L-shaped incision vs frown incision, and $P=0.096$ for frown incision vs conventional incision.

Figure 3 shows the changes in the corneal astigmatism after surgery. The centroid of preoperative corneal astigmatism was $0.43 \mathrm{D} @ 94^{\circ} \pm 1.78 \mathrm{D}$ and increased to $0.66 \mathrm{D}$ (a) $178^{\circ} \pm 1.99 \mathrm{D}$ postoperatively in eyes with conventional incision group. The centroid of preoperative corneal astigmatism was $0.16 \mathrm{D} @ 33^{\circ} \pm 1.20 \mathrm{D}$ and $0.39 \mathrm{D} @ 7^{\circ} \pm$ $0.79 \mathrm{D}$ but decreased to $0.10 \mathrm{D} @ 134^{\circ} \pm 1.12 \mathrm{D}$ and 0.35 $\mathrm{D} @ 171^{\circ} \pm 0.83 \mathrm{D}$ in eyes with L-shaped incision and frown incision, respectively. There was a significant difference in the SIA vector between groups; eyes with L-shaped incisions and frown incisions showed a lower SIA than that of the conventional incision at postoperative 6 months (SIA $\pm \mathrm{SD}, 0.86 \pm 0.85 \mathrm{D}, 0.63 \pm 0.37 \mathrm{D}$, and $1.70 \pm 1.27 \mathrm{D}$ for frown incision, L-shaped incision, and conventional incision, respectively; $P=0.004$, Table 2). Post hoc analysis using the Bonferroni test revealed the following: $P=0.008$ for conventional incision vs L-shaped incision, $\mathrm{P}>0.999$ for L-shaped incision vs frown incision, and $P=0.045$ for frown incision vs conventional incision. Eyes with frown incision showed the least amount of corneal astigmatism followed by the L-shaped incision and conventional incision groups at postoperative 6 months (corneal astigmatism $\pm \mathrm{SD},-0.76$ $\pm 0.33 \mathrm{D},-1.18 \pm 0.85 \mathrm{D}$, and $-1.71 \pm 1.52 \mathrm{D}$ for frown incision, L-shaped incision, and conventional incision, respectively; $P=0.004$ ). Post hoc analysis using the Bonferroni test revealed the following: $P=0.008$ for conventional incision vs L-shaped incision, $P=0.939$ for L-shaped incision vs frown incision, and $P=0.010$ for frown incision vs conventional incision. There was no difference in SE and mean keratometry between the 
Table I Demographic and Preoperative Ocular Characteristics of Enrolled Patients $(n=107)$

\begin{tabular}{|c|c|c|c|c|}
\hline & All Patients $(n=107)$ & Conventional Incision $(n=60)$ & L-Shaped Incision $(n=29)$ & Frown Incision $(n=18)$ \\
\hline \multirow{3}{*}{$\begin{array}{l}\text { Age, years } \\
\text { Range }\end{array}$} & $65.31 \pm 12.15$ & $66.91 \pm 12.26$ & $63.86 \pm 11.77$ & $62.38 \pm 12.14$ \\
\hline & $31-9 \mid$ & $43-91$ & $43-87$ & $31-83$ \\
\hline & & \multicolumn{3}{|c|}{$P=0.179, \dagger P=0.797$ for $C$ vs $L, P=1.000$ for $L$ vs $F, P=0.254$ for $F$ vs $C$} \\
\hline \multirow[t]{2}{*}{ Gender, male. (\%) } & $80(74.8)$ & $43(71.7)$ & $24(82.8)$ & $13(72.2)$ \\
\hline & & \multicolumn{3}{|l|}{$P=0.164$} \\
\hline \multirow{3}{*}{$\begin{array}{l}\text { UDVA, LogMAR } \\
\text { Range }\end{array}$} & $1.35 \pm 0.70$ & $1.39 \pm 0.65$ & $1.33 \pm 0.74$ & $1.21 \pm 0.84$ \\
\hline & $0.00-2.00$ & $0.16-2.00$ & $0.20-2.00$ & $0.00-2.00$ \\
\hline & & \multicolumn{3}{|c|}{$P=0.613, \dagger P=1.000$ for all subanalysis } \\
\hline \multirow{3}{*}{$\begin{array}{l}\text { CDVA, LogMAR } \\
\text { Range }\end{array}$} & $0.53 \pm 0.65$ & $0.58 \pm 0.68$ & $0.51 \pm 0.65$ & $0.36 \pm 0.53$ \\
\hline & $0.00-2.00$ & $0.00-2.00$ & $0.00-2.00$ & $0.00-2.00$ \\
\hline & & \multicolumn{3}{|c|}{$P=0.466, \dagger P=1.000$ for $C$ vs $L, P=1.000$ for $L$ vs $F, P=0.658$ for $F$ vs $C$} \\
\hline \multirow{3}{*}{$\begin{array}{l}\text { SE, D } \\
\text { Range }\end{array}$} & $6.72 \pm 5.60$ & $6.60 \pm 5.68$ & $6.66 \pm 5.82$ & $7.18 \pm 5.34$ \\
\hline & $-4.13-13.38$ & $-4.13-13.38$ & $-3.00-13.38$ & $-2.25-13.25$ \\
\hline & & \multicolumn{3}{|c|}{$P=0.938, \dagger P=1.000$ for all subanalysis } \\
\hline \multirow{3}{*}{$\begin{array}{l}\text { Km, D } \\
\text { Range }\end{array}$} & $43.84 \pm 1.46$ & $44.11 \pm 1.35$ & $43.74 \pm 1.66$ & $43.35 \pm 1.58$ \\
\hline & $40.64-47.65$ & $41.80-47.65$ & $40.71-47.28$ & $40.64-45.67$ \\
\hline & & \multicolumn{3}{|c|}{$P=0.177, \dagger P=0.861$ for $C$ vs $L, P=1.000$ for $L$ vs $F, P=0.208$ for $F$ vs $C$} \\
\hline \multirow{3}{*}{$\begin{array}{l}\text { Ka, D } \\
\text { Range }\end{array}$} & $-1.15 \pm 1.00$ & $-1.26 \pm 1.22$ & $-1.18 \pm 0.69$ & $-0.76 \pm 0.33$ \\
\hline & $-6.05-0.00$ & $-6.05-0.00$ & $-3.10-0.00$ & $-1.5 \mid-0.00$ \\
\hline & & \multicolumn{3}{|c|}{$P=0.202, \dagger P=1.000$ for $C$ vs $L, P=0.510$ for $L$ vs $F, P=0.228$ for $F$ vs $C$} \\
\hline \multirow{3}{*}{$\begin{array}{l}\mathrm{ECC}, / \mathrm{mm}^{2} \\
\text { Range }\end{array}$} & $2452.29 \pm 531.80$ & $2381.29 \pm 575.33$ & $2474.20 \pm 460.54$ & $2590.61 \pm 765.59$ \\
\hline & $1015.80-3979.00$ & $1015.80-3367.40$ & $17 \mid 7.17-3250.80$ & 1434.30-3979.00 \\
\hline & & \multicolumn{3}{|c|}{$P=0.437, \dagger P=1.000$ for $C$ vs $L, P=1.000$ for $L$ vs $F, P=0.600$ for $F$ vs $C$} \\
\hline \multirow{3}{*}{$\begin{array}{l}\text { IOP, } \mathrm{mmHg} \\
\text { Range }\end{array}$} & $15.98 \pm 4.92$ & $15.73 \pm 4.51$ & $16.75 \pm 4.36$ & $14.06 \pm 6.97$ \\
\hline & $8.00-29.00$ & $8.00-28.00$ & $9.00-29.00$ & $12.00-20.00$ \\
\hline & & \multicolumn{3}{|c|}{$P=0.459, \dagger P=0.930$ for $C$ vs $L, P=0.820$ for $L$ vs $F, P=0.867$ for $F$ vs $C$} \\
\hline \multirow{3}{*}{$\begin{array}{l}\text { Follow up period, month } \\
\text { Range }\end{array}$} & $36.67 \pm 18.86$ & $47.47 \pm 17.23$ & $28.50 \pm 5.61$ & $12.13 \pm 4.65$ \\
\hline & $6-81$ & $38-81$ & $13-37$ & $6-19$ \\
\hline & & \multicolumn{3}{|c|}{$\mathrm{P}<0.00 \mathrm{I}^{*}, \dagger \mathrm{P}<0.00 \mathrm{I}^{*}$ for all subanalysis } \\
\hline
\end{tabular}

Notes: Values are represented in frequency (percentage) for categorical variables, mean and standard deviation for continuous variables. ${ }^{\dagger}$ ANOVA was used to evaluate whether there is a significant difference between three groups. Bonferroni test was used for post hoc analysis.

Abbreviations: CDVA, corrected distance visual acuity; ECC, endothelial cell count; IOP, intraocular pressure; Ka, keratometric astigmatism; Km, mean keratometry; SE, spherical equivalent; UDVA, uncorrected distance visual acuity.

groups at 6 months after surgery $(\mathrm{SE},-0.19 \pm 0.77 \mathrm{D}$, $-0.07 \pm 0.89 \mathrm{D}$, and $-0.03 \pm 0.56 \mathrm{D}$ for conventional incision, L-shaped incision, and frown incision, respectively; $P=0.539$; mean keratometry, $43.88 \pm 1.59 \mathrm{D}$, $43.85 \pm 1.69 \mathrm{D}$, and $43.35 \pm 1.58 \mathrm{D}$ for conventional incision, L-shaped incision, and frown incision, respectively; $P=0.155)$.
Table 3 shows the postoperative complications according to the incision type. A total of 89 of 107 patients $(83.2 \%)$ experienced no complications during the follow-up period. Although the conventional incision group experienced postoperative complications the most frequently (12 of 60 patients [40.0\%]) when compared with the L-shaped incision or frown incision groups (2 of 

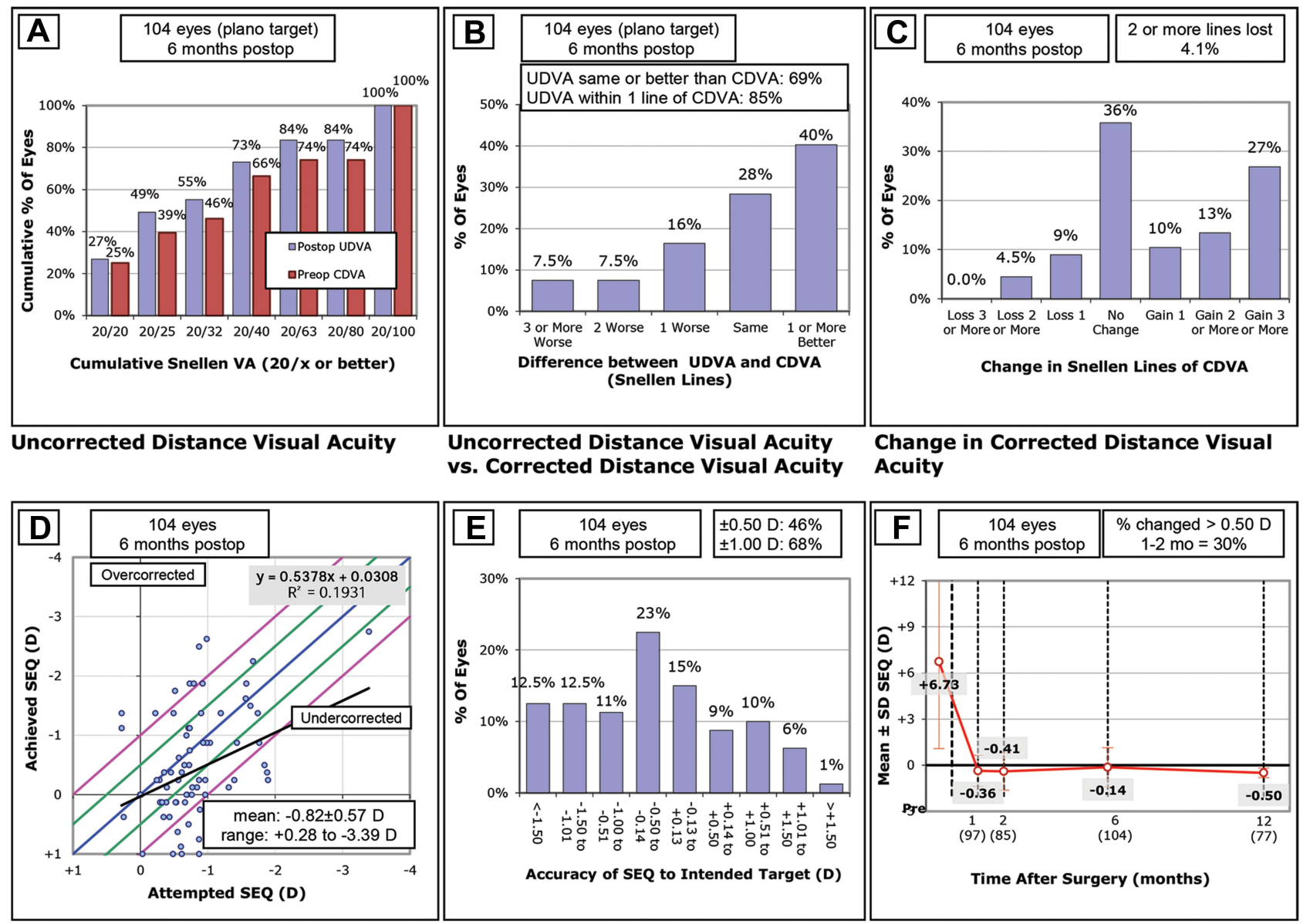

Spherical Equivalent Refraction Attempted vs Achieved
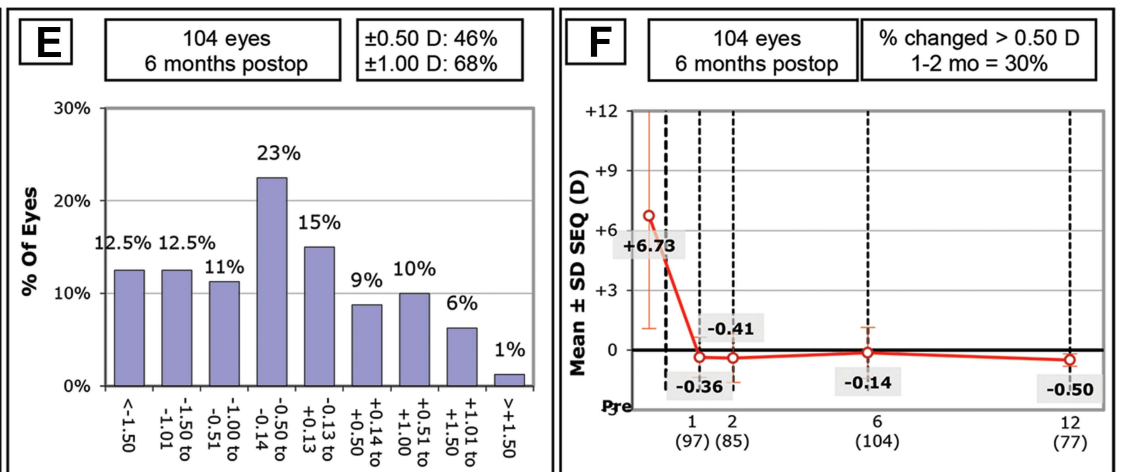

Accuracy of SEQ to Intended Target (D)

\section{Spherical Equivalent Refraction} Accuracy

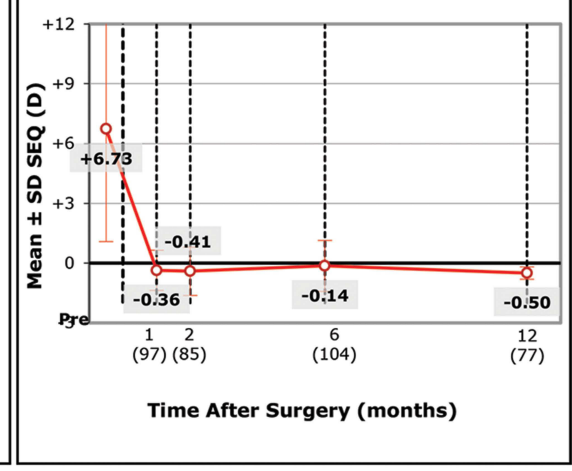

Spherical Equivalent Refraction Stability

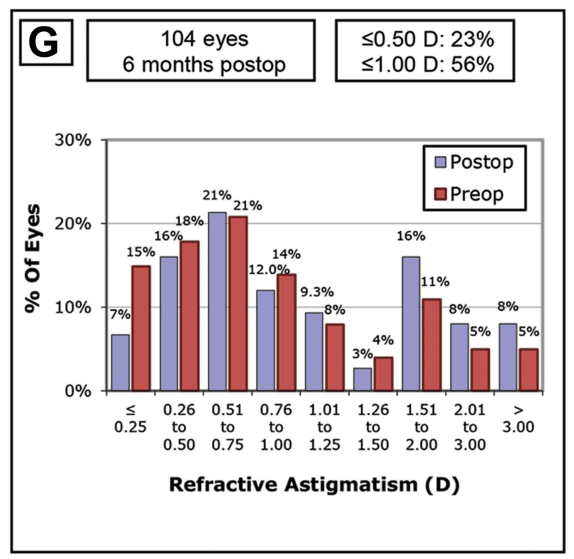

\section{Refractive Astigmatism}

Figure 2 Standard graphs for reporting refractive outcomes. (A) Uncorrected distance visual acuity (UDVA). (B) The difference between UDVA and corrected distance visual acuity (CDVA). (C) Change in CDVA, (D) The comparison between attempted spherical equivalent (SEQ) refraction and achieved SEQ refraction. (E) The accuracy of SEQ to the intended target. (F) Spherical equivalent refraction stability after surgery. (G) The comparison between preoperative and postoperative refractive astigmatism.

$29[6.9 \%]$ and 4 of $18[22.2 \%]$, respectively), there was no significant difference between groups $(P=0.223)$. The most frequent complication in the present data was the disenclavation of the haptic (11 of 107 patients
[10.3\%]), regardless of the incision type ( 8 of 60 patients in the conventional incision group [13.3\%], 2 of 29 in the L-shaped incision group [6.9\%], and 1 of 18 patients in the frown incision group [5.5\%]; $P=0.519)$. We 
Table 2 Comparison of the Postoperative 6 Month Analysis $(n=107)$

\begin{tabular}{|c|c|c|c|c|}
\hline & All Patients $(n=107)$ & Conventional Incision $(n=60)$ & L-Shaped Incision $(n=29)$ & Frown Incision $(n=15)$ \\
\hline \multirow[t]{3}{*}{ UDVA, LogMAR } & $0.32 \pm 0.41$ & $0.47 \pm 0.49$ & $0.24 \pm 0.23$ & $0.06 \pm 0.11$ \\
\hline & $0.00-2.00$ & $0.00-2.00$ & $0.00-1.00$ & $0.00-0.40$ \\
\hline & & \multicolumn{3}{|c|}{$P=0.003, P=0.151$ for $C$ vs $L, P=0.536$ for $L$ vs $F, P=0.003$ for $F$ vs $C$} \\
\hline \multirow[t]{3}{*}{ CDVA, LogMAR } & $0.18 \pm 0.32$ & $0.27 \pm 0.39$ & $0.15 \pm 0.24$ & $0.02 \pm 0.05$ \\
\hline & $0.00-2.00$ & $0.00-2.00$ & $0.00-1.00$ & $0.00-0.40$ \\
\hline & & \multicolumn{3}{|c|}{$P=0.035, P=0.089$ for $C$ vs $L, P=0.728$ for $L$ vs $F, P=0.096$ for $F$ vs $C$} \\
\hline \multirow[t]{3}{*}{ SE, D } & $-0.14 \pm 0.83$ & $-0.19 \pm 0.77$ & $-0.07 \pm 0.89$ & $-0.03 \pm 0.56$ \\
\hline & $-3.25-2.13$ & $-3.25-1.38$ & $-3.00-2.13$ & $-1.25-1.38$ \\
\hline & & \multicolumn{3}{|c|}{$P=0.539, P<0.001$ for all subanalysis } \\
\hline \multirow[t]{3}{*}{$\mathrm{Km}, \mathrm{D}$} & $43.74 \pm 1.64$ & $43.88 \pm 1.59$ & $43.85 \pm 1.69$ & $43.35 \pm 1.58$ \\
\hline & $40.00-47.50$ & $40.00-47.50$ & $40.50-47.25$ & $40.64-45.67$ \\
\hline & & \multicolumn{3}{|c|}{$P=0.155, P>0.999$ for $C$ vs $L, P=0.510$ for $L$ vs $F, P=0.163$ for $F$ vs $C$} \\
\hline \multirow[t]{3}{*}{$\mathrm{Ka}, \mathrm{D}$} & $-1.40 \pm 1.29$ & $-1.71 \pm 1.52$ & $-1.18 \pm 0.85$ & $-0.76 \pm 0.33$ \\
\hline & $-7.75-0.00$ & $-7.75-0.00$ & $-3.50--0.25$ & $-2.00--0.17$ \\
\hline & & \multicolumn{3}{|c|}{$P=0.004, P=0.188$ for $C$ vs $L, P=0.939$ for $L$ vs $F, P=0.010$ for $F$ vs $C$} \\
\hline \multirow[t]{3}{*}{ SIA, D } & $1.28 \pm 1.14$ & $1.70 \pm 1.27$ & $0.63 \pm 0.37$ & $0.86 \pm 0.85$ \\
\hline & $0.09-4.46$ & $0.09-4.46$ & $0.09-1.23$ & $0.09-3.61$ \\
\hline & & \multicolumn{3}{|c|}{$P=0.004, P=0.008$ for $C$ vs $L, P>0.999$ for $L$ vs $F, P=0.045$ for $F$ vs $C$} \\
\hline IOP, $\mathrm{mmHg}$ & $14.83 \pm 2.88$ & $14.98 \pm 2.55$ & $14.03 \pm 3.54$ & $15.64 \pm 2.52$ \\
\hline \multirow[t]{2}{*}{ Range } & $8.00-24.00$ & $10.00-24.00$ & $9.00-19.00$ & $13.00-21.00$ \\
\hline & & \multicolumn{3}{|c|}{$P=0.154, P=0.422$ for $C$ vs $L, P>0.999$ for $L$ vs $F, P>0.999$ for $F$ vs $C$} \\
\hline
\end{tabular}

Notes: ANOVA was used to evaluate whether there is a significant difference between three groups. Bonferroni test was used for post hoc analysis.

Abbreviations: CDVA, corrected distance visual acuity; IOP, intraocular pressure; Ka, keratometric astigmatism; Km, mean keratometry; SE, spherical equivalent; SIA, surgically induced astigmatism vector; UDVA, uncorrected distance visual acuity.

detected a peaked or oval pupil and cystoid macular edema in 5 of 107 eyes (4.7\%) postoperatively without any correlation to the incision type $(P=0.362$ and $P=$ 0.146 , respectively). There were no cases of corneal decompensation, wound leakage, postoperative hypotony, retinal detachment, vitreous hemorrhage, or endophthalmitis.

\section{Discussion}

In the present study, we found that the modified sclerocorneal incisions (both the L-shaped incision and frown incision) improved refractive outcomes after retropupillary iris-claw IOL implantation through an associated reduction in SIA. Accordingly, eyes with modified sclerocorneal incisions showed a significantly better UDVA when compared with that of conventional 5.5-mm-size sclerocorneal incisions.
Increased postoperative astigmatism after IOL exchange has always been a critical hurdle for good postoperative vision. ${ }^{6,11-13}$ Kristianslund et al reported that the mean SIA magnitude was $1.12 \pm 0.85 \mathrm{D}$ at 6 months after a $5.5-\mathrm{mm}$ scleral pocket arcuate incision and retropupillary iris-claw IOL implantation, which was significantly higher than the SIA of the IOL reposition. ${ }^{13}$ Choi et al also reported a significant increase in corneal astigmatism after a $5.5-\mathrm{mm}$ sclerocorneal incision and retropupillary iris-claw IOL implantation; although, no information regarding SIA was included in the data. ${ }^{11}$ In the present study, the SIA was $1.70 \pm 1.27 \mathrm{D}$ for the conventional incision, but it was reduced to $0.63 \pm 0.37 \mathrm{D}$ and $0.86 \pm$ $0.85 \mathrm{D}$ when the incision was modified into an L-shaped or frown incision. A small-sized corneal incision could be used when the dislocated IOL is cut before extraction and the new IOL is foldable; ${ }^{19}$ however, the Artisan aphakia 
A

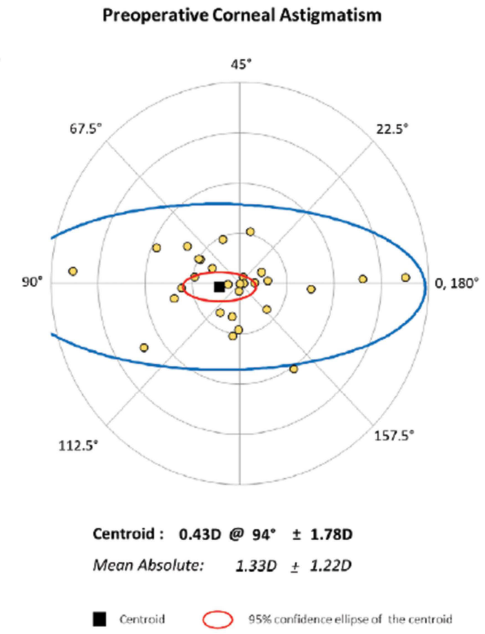

- centroid $\bigcirc 95 \%$ confidenceellipse of the centroil
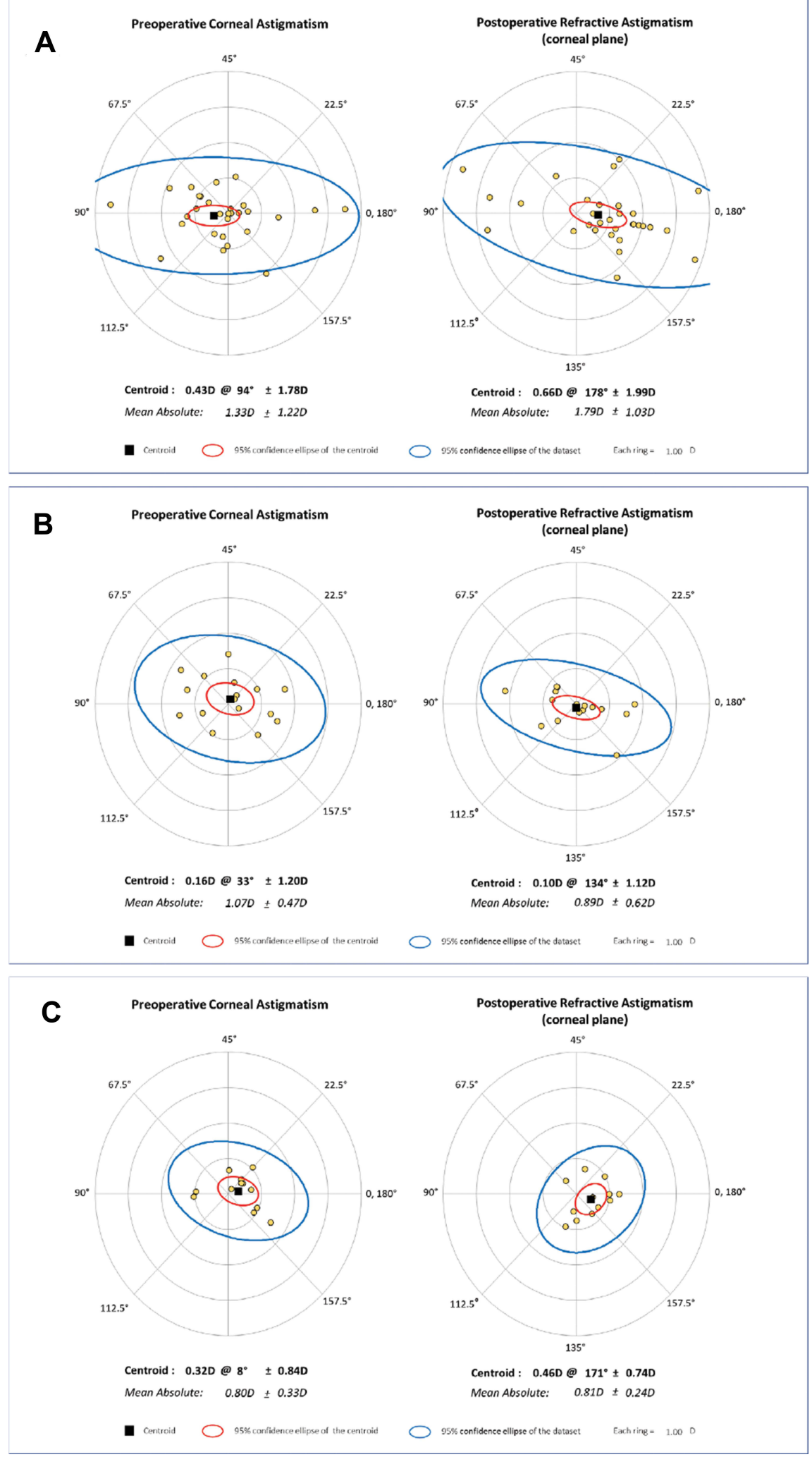

Figure 3 Cumulative histogram of the magnitude of the preoperative corneal and postoperative refractive astigmatism, vertexed to the corneal plane; (A) a conventional 5.5-mm sclerocorneal incision, (B) L-shaped incision, and (C) frown incision. 
Table 3 Comparisons of the Postoperative Complications $(n=107)$

\begin{tabular}{|c|c|c|c|c|}
\hline & All Patients $(n=107)$ & Conventional Incision $(n=60)$ & L-Shaped Incision $(n=29)$ & Frown Incision $(n=18)$ \\
\hline No complication & $89(83.2 \%)$ & $\begin{array}{l}48(60.0 \%) \\
P=0.223^{*}\end{array}$ & $27(93.1 \%)$ & $14(77.8 \%)$ \\
\hline Corneal decompensation & $0(0.0 \%)$ & & & \\
\hline Peaked or oval pupil & $5(4.7 \%)$ & $\begin{array}{l}4(6.7 \%) \\
P=0.362^{*}\end{array}$ & $0(0.0 \%)$ & I (5.6\%) \\
\hline Wound leakage & $0(0.0 \%)$ & & & \\
\hline Postoperative hypotomy & $0(0.0 \%)$ & & & \\
\hline Disenclavation & II (10.3\%) & $\begin{array}{l}8(13.3 \%) \\
P=0.519 *\end{array}$ & $2(6.9 \%)$ & I (5.5\%) \\
\hline Cystoid macular edema & $5(4.7 \%)$ & $\begin{array}{l}3(5.0 \%) \\
P=0.146^{*}\end{array}$ & $0(0.0 \%)$ & $2(11.1 \%)$ \\
\hline Retinal detachment & $0(0.0 \%)$ & & & \\
\hline Vitreous hemorrhage & $0(0.0 \%)$ & & & \\
\hline Endophthalmitis & $0(0.0 \%)$ & & & \\
\hline
\end{tabular}

Note: *ANOVA was used to evaluate whether there is a significant difference between three groups.

IOL is made of a rigid biomaterial and is therefore not foldable. Our experience with the modified sclerocorneal incision suggests that postoperative visual quality in eyes undergoing retropupillary iris-claw IOL implantation can be improved. There were no surgical complications related to the extraction of dislocated IOLs even in the instance of extracting a large-sized $(6.0 \mathrm{~mm})$ PMMA IOL.

The complication rates of the present study were favorable when compared with previous studies, as 89 of 107 eyes (83.2\%) showed no complications in the postoperative period. Although the rate of abnormal iris shape, and cystoid macular edema was similar to that of other studies, ${ }^{4,11}$ there were no cases of wound leakage, iris prolapse, vitreous band to the wound, or abnormal intraocular pressure. We assumed that concurrent vitrectomy, which helps to maintain stable intraoperative intraocular pressure, contributed to the relatively low postoperative complication rate. In addition, use of the modified incisions was associated with a reduced risk of postoperative complications when compared with traditionally larger incision sizes. The disenclavation rate was $10.3 \%$ in the present study. The disenclavation rate in the literature varies from $0.0 \%$ to $9.8 \%{ }^{4,6-11,20-23}$ As Kim et al previously discussed, the strength of the tissue grasping, atrophy of iris tissue, and postoperative ocular trauma may affect the disenclavation rate. $^{20}$

The percentage of eyes within $1.00 \mathrm{D}$ of target refraction was low $(68 \%)$ in the present study. There is no consensus on the optimized A constant and IOL formula for retropupillary Artisan iris-claw IOLs. We have used the SRK/T formula and an optimized A constant of 116.9 suggested by the ULIB and IOL CON webpages. Mohr et $\mathrm{al}^{6}$ suggested 116.8 as an optimal A constant for retropupillary Artisan iris-claw IOLs. Galvis et al showed good results using Haigis formula and A constant of 117.5 in an eye with anterior megalophthalmos. ${ }^{4}$ Further studies on the optimized A constant and IOL formula for retropupillary Artisan iris-claw IOLs are warranted to minimize postoperative refractive error.

Increased postoperative astigmatism and postoperative complications from large sclerocorneal incisions have been critical shortcomings when considering IOL exchange using the retropupillary iris-claw IOL. Using the modified scleral tunnel incision, either L-shaped incision or frown incision resulted in a significantly smaller amount of astigmatism when compared with conventional incision. The modified incisions enabled the extraction of the dislocated IOL without having to cut the IOL in the anterior chamber, which may cause endothelial or iris damage. Even a dislocated PMMA IOL with an optic size larger than $6.0 \mathrm{~mm}$ could be extracted through the modified incisions without enlarging the incision size owing to the higher elasticity of scleral tissue compared with that of the corneal tissue ${ }^{24}$ (Figure 4). 

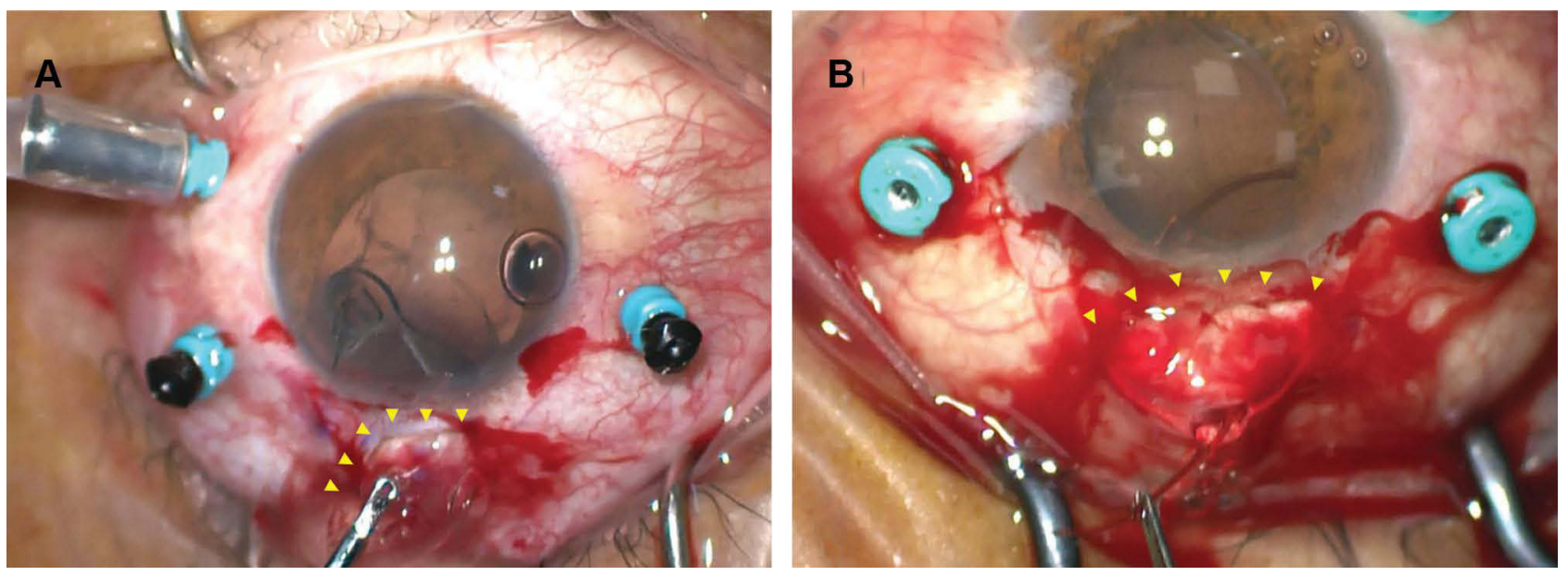

Figure 4 Representative surgical images of the (A) L-shaped incision and (B) frown incision.

The modified sclerocorneal incision, such as the L-shaped incision and frown incision, resulted in remarkably low postoperative astigmatism and complications. There are several methods for vector analysis of astigmatism. The Alpins method is a vectorial analysis that focuses on changes in astigmatism after surgery. This method has the strength that it can provide a complete description of the astigmatic correction achieved with a specific modality of treatment. However, specific software is required to statistically analyze the outcomes. Another well-known tool is the Thibos method, which provides a straightforward comparison between preoperative and postoperative refractive power vectors without specific software. ${ }^{25,26}$ Although we used the Alpins methods for the present data, it would be interesting to analyze the current data with the Thibos method. This study is limited by its retrospective nature and relatively small patient numbers in each subgroup. Further study using a prospective study design is warranted to precisely evaluate the effect of the different types of sclerocorneal incisions on IOL exchange.

\section{Disclosure}

The authors report no conflicts of interest in this work.

\section{References}

1. Worst JG. Iris claw lens. J Am Intraocul Implant Soc 1980;6:166-167.

2. Amar L. Posterior chamber iris claw lens. Am Intra Ocular Implant Soc. $1980 ; 6: 27$.

3. Rijneveld WJ, Beekhuis WH, Hassman EF, Dellaert MMMJD, Geerards AJM. Iris claw lens: anterior and posterior iris surface fixation in the absence of capsular support during penetrating keratoplasty. $J$ Refract Corneal Surg 1994; 10(1):14-19.

4. Galvis V, Tello A, Miotto G, Rangel CM. Artisan aphakic lens for cataract surgery in anterior megalophthalmos. Case Rep Ophthalmol 2012; 3(3):428- 433. doi:10.1159/000346074
5. Menezo JL, Martinez MC, Cisneros AL. Iris-fixated Worst claw versus sulcus-fixated posterior chamber lenses in the absence of capsular support. J Cataract Refract Surg. 1996;22(10):1476-1484. doi:10. 1016/S0886-3350(96)80151-9

6. Mohr A, Hengerer F, Eckardt C. Retropupillare Fixation der Irisklauenlinse bei Aphakie. Einjahresergebnisse einer neuen Implantationstechnik [Retropupillary fixation of the iris claw lens in aphakia. 1 year outcome of a new implantation techniques]. Ophthalmologe. 2002;99(7):580-583. doi:10.1007/s00347-001-0563-z

7. Gonnermann J, Klamann MK, Maier AK, et al. Visual outcome and complications after posterior iris-claw aphakic intraocular lens implantation. J Cataract Refract Surg. 2012;38(12):2139-2143. doi:10.1016/j.jcrs.2012.07.035

8. Forlini M, Soliman W, Bratu A, et al. Long-term follow-up of retropupillary iris-claw intraocular lens implantation: a retrospective analysis. BMC Ophthalmol. 2015;15:143. doi:10.1186/s12886-015-0146-4

9. Touriño Peralba R, Lamas-Francis D, Sarandeses-Diez T, MartínezPérez L, Rodríguez-Ares T. Iris-claw intraocular lens for aphakia: can location influence the final outcomes? J Cataract Refract Surg. 2018;44(7):818-826. doi:10.1016/j.jcrs.2018.05.010

10. Toro MD, Longo A, Avitabile T, et al. Five-year follow-up of secondary iris-claw intraocular lens implantation for the treatment of aphakia: anterior chamber versus retropupillary implantation. PLoS One. 2019;14(4):e0214140. doi:10.1371/journal. pone.0214140

11. Choi EY, Lee CH, Kang HG, et al. Long-term surgical outcomes of primary retropupillary iris claw intraocular lens implantation for the treatment of intraocular lens dislocation. Sci Rep. 2021;11(1):726. doi:10.1038/s41598-020-80292-3

12. Gimbel HV, Condon GP, Kohnen T, Olson RJ, Halkiadakis I. Late in-the-bag intraocular lens dislocation: incidence, prevention, and management. J Cataract Refract Surg. 2005;31(11):2193-2204. doi:10.1016/j.jcrs.2005.06.053

13. Kristianslund O, Østern AE, Drolsum L. Astigmatism and refractive outcome after late in-the-bag intraocular lens dislocation surgery: a randomized clinical trial. Invest Ophthalmol Vis Sci. 2017;58 (11):4747-4753. doi:10.1167/iovs.17-22723

14. Singer JA. Frown incision for minimizing induced astigmatism after small incision cataract surgery with rigid optic intraocular lens implantation. J Cataract Refract Surg. 1991;17:677-688. doi:10.10 16/S0886-3350(13)80683-9

15. Hennekes RL, Van den Dooren KA. Asymmetric L-shaped corneal no-stitch tunnel incisions for cataract surgery. $J$ Cataract Refract Surg. 1999;25(4):550-555. doi:10.1016/S0886-3350(99)80054-6 
16. Reinstein DZ, Archer TJ, Randleman JB. JRS standard for reporting astigmatism outcomes of refractive surgery. J Refract Surg. 2014;30 (10):654-659. doi:10.3928/1081597X-20140903-01

17. Alpins N. Astigmatism analysis by the Alpins method. J Cataract Refract Surg. 2001;27(1):31-49. doi:10.1016/S0886-3350(00)00 798-7

18. Abulafia A, Koch DD, Holladay JT, Wang L, Hill W. Pursuing perfection in intraocular lens calculations: IV. Rethinking astigmatism analysis for intraocular lens-based surgery: suggested terminology, analysis, and standards for outcome reports. J Cataract Refract Surg. 2018;44(10):1169-1174. doi:10.1016/j.jcrs.2018.07.027

19. Whang WJ, Kwon H, Jeon S. Application of a four-flanged intrascleral fixation technique for toric and multifocal intraocular lenses. Am J Ophthalmol Case Rep. 2020;20:100933. doi:10.1016/j.ajoc.2020. 100933

20. Kim MS, Park SJ, Joo K, et al. Single-Haptic Dislocation of Retropupillary Iris-Claw Intraocular Lens: Outcomes of Reenclavation. Ophthalmic Surg Lasers Imaging Retina. 2020 Jul 1;51(7):384-390. doi:10.3928/23258160-20200702-03

21. Choragiewicz T, Rejdak R, Grzybowski A, et al. Outcomes of Sutureless Iris-Claw Lens Implantation. $J$ Ophthalmol. 2016;2016:7013709. doi:10.1155/2016/7013709
22. Jare NM, Kesari AG, Gadkari SS, Deshpande MD. The posterior irisclaw lens outcome study: 6-month follow-up. Indian J Ophthalmol. 2016;64(12):878-883. doi:10.4103/0301-4738.198843

23. Mora P, Calzetti G, Favilla S, et al. Comparative Analysis of the Safety and Functional Outcomes of Anterior versus Retropupillary Iris-Claw IOL Fixation. $J$ Ophthalmol. 2018;2018:8463569. doi: $10.1155 / 2018 / 8463569$

24. Asejczyk-Widlicka M, Pierscionek BK. The elasticity and rigidity of the outer coats of the eye. Br J Ophthalmol. 2008;92(10):1415-1418. doi:10.1136/bjo.2008.140178

25. Thibos LN, Horner D. Power vector analysis of the optical outcome of refractive surgery. J Cataract Refract Surg. 2001;27(1):80-85. doi:10.1016/S0886-3350(00)00797-5

26. Thibos LN, Wheeler W, Horner D. Power vectors: an application of Fourier analysis to the description and statistical analysis of refractive error. Optom Vis Sci. 1997;74(6):367-375. doi:10.1097/00006324199706000-00019
Clinical Ophthalmology

\section{Publish your work in this journal}

Clinical Ophthalmology is an international, peer-reviewed journal covering all subspecialties within ophthalmology. Key topics include: Optometry; Visual science; Pharmacology and drug therapy in eye diseases; Basic Sciences; Primary and Secondary eye care; Patient Safety and Quality of Care Improvements. This journal is indexed on PubMed

Submit your manuscript here: https://www.dovepress.com/clinical-ophthalmology-journal
Dovepress

Central and CAS, and is the official journal of The Society of Clinical Ophthalmology (SCO). The manuscript management system is completely online and includes a very quick and fair peer-review system, which is all easy to use. Visit http://www.dovepress.com/ testimonials.php to read real quotes from published authors. 